\title{
THE BOUNDARY-LAYER RESISTANCE MODEL FOR UNSTIRRED ULTRAFILTRATION. A NEW APPROACH*
}

\author{
G.B. van den BERG** and C.A. SMOLDERS \\ Department of Chemical Technology, Twente University of Technology, P.O. Box 217, 7500 AE \\ Enschede (The Netherlands)
}

\section{Summary}

The possibility to analyse concentration polarization phenomena during unstirred dead-end ultrafiltration by the boundary layer resistance theory has been shown by Nakao et al. [1]. Experimental data on the ultrafiltration of $\mathrm{BSA}$ at $\mathrm{pH} 7.4$, at various concentrations and pressures, were analysed by this model and by a new version of the model in this paper. Instead of the assumption of the cake filtration theory, the new version of the model uses the unsteady state equation for solute mass transport to predict flux data by computer simulations. This approach requires no assumptions concerning the concentration at the membrane, the concentration profile or the specific resistance of the boundary layer. The computer simulations agree very well with the experimental data. Many agreements with Nakao's analyses are confirmed and some new data on the concentration polarization phenomena are obtained.

\section{Introduction}

The phenomenon of flux decline in protein ultrafiltration has been studied by several investigators, each of them usually emphasizing one of the aspects of membrane fouling. The subjects studied most, in relation to the flux decline, are adsorption [2], pore-blocking [3], deposition of solute [4] and concentration polarization phenomena, for which several models have been developed [5-9]. The latter models make use of one or more of the properties of the solute: an increased osmotic pressure difference $[5,6]$, formation of a gel layer $[8,9]$ or a limited permeability of the concentrated layer near the membrane which can be described by the boundary layer resistance model [7]. One of the problems in the study of the cross-flow ultrafiltration process is to describe the mass transfer coefficient properly. The numerous relations for the mass transfer coefficient are all (semi-)empirical, and in some cases show large deviations when checked with experimental data. To overcome this problem the

\footnotetext{
*Paper presented at the Workshop on Concentration Polarization and Membrane Fouling, University of Twente, The Netherlands, May 18-19, 1987.

**'To whom correspondence should be addressed.
} 
study of concentration polarization can be simplified to the case of unstirred dead-end ultrafiltration. Nakao et al. [1] used the boundary layer resistance model adapted to a cake filtration type of description to analyse the experimental flux behaviour during the ultrafiltration of dextrans and polyethylene glycols. This model gave some promising results, but it could not describe some of the experimentally obtained flux data. Furthermore, the model was unable to predict the experimental flux behaviour without the need for several other experiments to obtain the necessary parameters.

The objectives of this investigation are to develop a more accurate and predictive description of the flux behaviour in ultrafiltration. This has been achieved by adapting the boundary layer resistance model and using dynamic equations for describing the phenomena near the membrane interface. The validity of the model has also been extended to the filtration of protein solutions (BSA). The simulated flux data have been compared both with the experimental ultrafiltration results and with the results obtained with the model of Nakao et al. With the improved model, more information can be obtained about the ultrafiltration process, while less parameters are necessary to describe the flux behaviour than with the original model [1].

The newly developed boundary layer resistance model has been successfully applied (and experimentally verified) to various applied pressures in the ultrafiltration process, to several concentrations and to different types of membranes.

\section{Theory}

This section on the theory of dead-end ultrafiltration consists of three parts: (1) the general principles of the boundary layer resistance model, (2) the adaptation of these principles to a cake filtration type of description, and (3) the adaptation to a dynamic model, which is the new approach.

\section{The general principles of the boundary layer resistance model}

According to the boundary layer resistance model the permeate flux $J_{\mathrm{v}}$ can be described by:

$J_{\mathrm{v}}=\Delta P /\left[\eta_{0} \cdot\left(R_{\mathrm{m}}+R_{\mathrm{bl}}\right)\right]$

where $R_{\mathrm{m}}$ and $R_{\mathrm{bl}}$ are the hydraulic resistances of the membrane and the concentrated boundary layer, respectively, $\Delta P$ is the applied pressure and $\eta_{0}$ is the dynamic viscosity of the solvent. The resistance $R_{\mathrm{bl}}$ is a cumulative effect of the diminished permeability of the concentrated layer near the membrane, and can be described by

$R_{\mathrm{bl}}=\int_{0}^{\delta}, r_{\mathrm{bl}}(x) \mathrm{d} x=\int_{0}^{\delta}, p(x)^{-1} \mathrm{~d} x$ 
where $r_{\mathrm{bl}}(x)$ is the specific resistance of a thin concentrated layer $\mathrm{d} x$ and $p(x)$ is the permeability of that layer. The basic principle of the boundary layer resistance theory is the correspondence of the permeability of a concentrated layer for the solvent near a membrane interface and the permeability of a solute in a stagnant solution, as occurring during a sedimentation experiment. This latter relationship can be described by [10]

$p=\left[\eta_{0} \cdot s(C)\right] /\left[C \cdot\left(1-v_{1} / v_{0}\right)\right]$

where $p$ is the permeability, $s(C)$ is the sedimentation coefficient at concentration $C$ and $v_{0}$ and $v_{1}$ are the partial specific volumes of the solvent and the solute, respectively.

2. The boundary layer resistance model adapted to the cake filtration type of description [1]

Following the cake filtration description, the concentration profile near the membrane is represented as given in Fig. 1. The thickness of the boundary layer $\delta$, having a constant concentration $C_{\mathrm{bl}}$, can be obtained from the mass balance

$C_{\mathrm{b}} \cdot R_{\mathrm{obs}} \cdot V_{\mathrm{p}}=\delta \cdot A \cdot C_{\mathrm{bl}}$

in which $C_{\mathrm{b}}$ is the bulk concentration, $R_{\mathrm{obs}}$ is the observed retention, $V_{\mathrm{n}}$ is the accumulative permeate volume and $A$ is the membrane area. Now the resistance of the boundary layer can be calculated by

$R_{\mathrm{bl}}=\delta \cdot r_{\mathrm{bl}}$

in which the specific resistance $r_{\mathrm{bl}}$ is constant over the boundary layer $\delta$. Combining eqns. (1), (4) and (5) results in

$1 / J_{\mathrm{v}}=1 / J_{\mathrm{w}}+\left(\eta_{\mathrm{o}} \cdot C_{\mathrm{b}} \cdot R_{\mathrm{obs}} / \Delta P\right) \cdot\left(r_{\mathrm{bl}} / C_{\mathrm{bl}}\right) \cdot\left(V_{\mathrm{p}} / A\right)$

in which $\left(r_{\mathrm{bl}} / C_{\mathrm{bl}}\right)$ is a quantity called the flux decline index and $\left(V_{\mathrm{p}} / A\right)$ is the

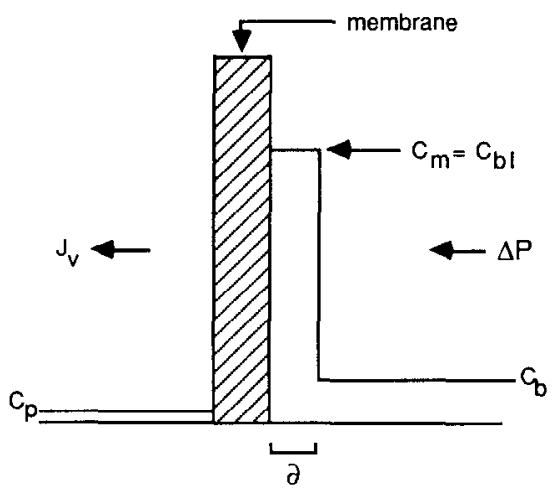

Fig. 1. The concentration profile according to the cake-filtration model. 
specific cumulative permeate volume. In order to analyse experimental results, where usually $1 / J_{\mathrm{v}}$ is plotted as a function of $\left(V_{\mathrm{p}} / A\right)$, eqn. (6) is transformed into

$\mathrm{d}\left(1 / J_{\mathrm{v}}\right) / \mathrm{d}\left(V_{\mathrm{p}} / A\right)=\left(\eta_{0} \cdot C_{\mathrm{b}} \cdot R_{\mathrm{obs}} / \Delta P\right) \cdot\left(r_{\mathrm{b} 1} / C_{\mathrm{b} 1}\right)$

With the known values of $C_{\mathrm{b}}, \eta_{\mathrm{o}}, R_{\mathrm{obs}}$ and $\Delta P$, the flux decline index $r_{\mathrm{bl}} / C_{\mathrm{bl}}$ can be determined from one set of experiments. From this value the boundary layer concentration $C_{\mathrm{bl}}$ can be calculated by making use of the relation for the sedimentation coefficient (eqn. 8).

$r_{\mathrm{bl}} / C_{\mathrm{cl}}=\left(1-v_{1} / v_{0}\right) /\left[\eta_{0} \cdot s\left(C_{\mathrm{bl}}\right)\right]$

provided that the dependence of $s$ on the concentration is known. In the discussion section, results obtained in this way will be compared with the simulated ultrafiltration flux data.

\section{The new approach to the boundary layer resistance model}

Contrary to the former model, the concentration profile near the membrane interface will be calculated without making any assumptions concerning the concentration at the membrane or the shape of the concentration profile. In this situation the general mass balance equation for the solute reads

$\partial C / \partial t=-J_{\mathrm{v}} \cdot \partial C / \partial x+D \cdot \partial^{2} C / \partial x^{2}$

where $-J_{\mathrm{v}} \cdot \partial C / \partial x$ represents the convective solute transport towards the membrane $(\partial C / \partial x$ is negative, $x$ is the distance into the boundary layer $)$ and $D \cdot \partial^{2} C / \partial x^{2}$ represents the back-diffusion as a result of the concentration gradient. The boundary and initial conditions are:

$t=0: C=C_{\mathrm{b}}$

$x=\delta: C=C_{\mathrm{b}}$

$x=0: J_{\mathrm{v}} \cdot C_{\mathrm{m}}=D \cdot(\partial C / \partial x)_{x=0}+\left(1-R_{\mathrm{obs}}\right) \cdot J_{\mathrm{v}} \cdot C_{\mathrm{b}}$

where $\delta$ is the thickness of the concentration polarization layer. Using the equations mentioned above, the shape of the concentration profile can be expected to be as shown in Fig. 2.

If the diffusion coefficient and the concentration of the bulk were constant, this set of equations could be solved analytically [11]. However, in the realistic situation many variables are a function of concentration, hence the differential equation can be solved numerically only.

The concentration dependence of the viscosity was not used for correction of the increased visocity near the membrane interface. This is not necessary because the appropriate sedimentation coefficients (i.e. at the actual boundary layer concentrations) are used to calculate the resistance of the concentrated layer. 


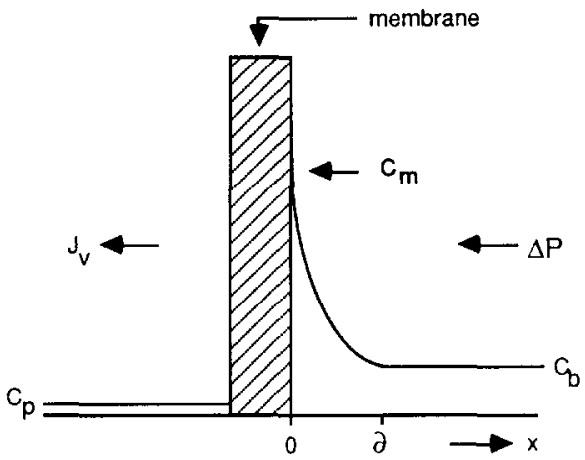

Fig. 2. The concentration profile during dead-end ultrafiltration according to the new approach.

The equations used to solve the problem numerically are eqns. (1), (2), (3) and (9), where the dependence of the diffusion coefficient and the sedimentation coefficient on the concentration has to be included. Without any assumptions concerning the concentration at the membrane or the specific resistance of the concentrated layer, all ultrafiltration characteristics can be calculated, including the concentration profile near the membrane. The only experimental data needed for simulating an ultrafiltration experiment are the retention and the hydraulic resistance of the membrane.

The comparison between the results of this model and that of Nakao will be made for the major part by comparing the $\mathrm{d}\left(1 / J_{\mathrm{v}}\right) / \mathrm{d}\left(V_{\mathrm{p}} / A\right)$ values, which can be calculated easily from the computed flux data.

\section{Experimental}

\section{Materials}

All experiments were performed using bovine serum albumin (BSA) Cohn fraction V from Sigma Chemical Company, lot no. 45F-0064 as a solute. The solutions of BSA were prepared in a phosphate buffer at $\mathrm{pH} 7.4 \pm 0.05$ with 0.1 $M \mathrm{NaCl}$ added, to give a solution with ionic strength $I=0.125 \mathrm{~N}$. The concentrations of the BSA solutions were determined, after producing a calibration curve, by using a Hitachi-Perkin Elmer double beam spectrophotometer model 124 , operating at $280 \mathrm{~nm}$. Normally the extinction coefficient $E^{280}$ was 0.66 . The water used was demineralized by ion exchange, ultrafiltered and finally hyperfiltered. The membranes used in the dead-end ultrafiltration experiments were Amicon Diaflo membranes. In most experiments YM-30 membranes (regenerated cellulose acetate, cut-off 30,000 daltons) were used and also experiments were performed using PM-30 membranes (polysulfone, cutoff 30.000 daltons ). 


\section{Equipment}

The unstirred dead-end ultrafiltration experiments were performed in an Amicon cell, type 401S, which was adapted to make thermostatting at $20^{\circ} \mathrm{C}$ possible. The total membrane surface was $38.48 \mathrm{~cm}^{2}$. To avoid fouling in the blank experiment by, for example, colloids present in the system, the water was filtered in-line through a $0.22 \mu \mathrm{m}$ PVDF Millipore microfiltration membrane. The amount of permeate was determined gravimetrically, while the amount of permeate collected in time was registered by a recorder. Figure 3 gives a general outline of the equipment.

The simulations of ultrafiltration experiments were performed by using either a DEC-2060 or a VAX-8650 computer, in both cases with the help of several library routines to solve the differential equations. The main routine used is the D03PBF-NAG FORTRAN library routine document, which integrates a system of linear or nonlinear parabolic partial differential equations in one space variable [12].

'The sedimentation and diffusion experiments were performed in a Beckman analytical ultracentrifuge, model $\mathrm{E}$, equipped with Schlieren optics and a temperature control system. Centrepieces of $1.5,3$ and $12 \mathrm{~mm}$ were used, the temperature was $20^{\circ} \mathrm{C}$ and the rotation speed was $40,000 \mathrm{rpm}$ during the sedimentation experiments and $3400 \mathrm{rpm}$ during the diffusion experiments. The concentration range measured was from 2.5 to $450 \mathrm{~kg} / \mathrm{m}^{3}$ for the sedimentation experiments and 6 to $215 \mathrm{~kg} / \mathrm{m}^{3}$ for the diffusion experiments.

\section{Methods}

To obtain the experimental flux data, the following procedure was employed: (a) detcrmine the water flux; (b) replace the water by the BSA solution at $20^{\circ} \mathrm{C}$; (c) register the cumulative permeate weight as a function of time; (d) remove the BSA solution and rinse the ultrafiltration cell thoroughly; (e) determine the water flux again. To calculate the permeate volume, the density of the permeate was taken as $1000 \mathrm{~kg} / \mathrm{m}^{3}$. In order to determine the protein re-

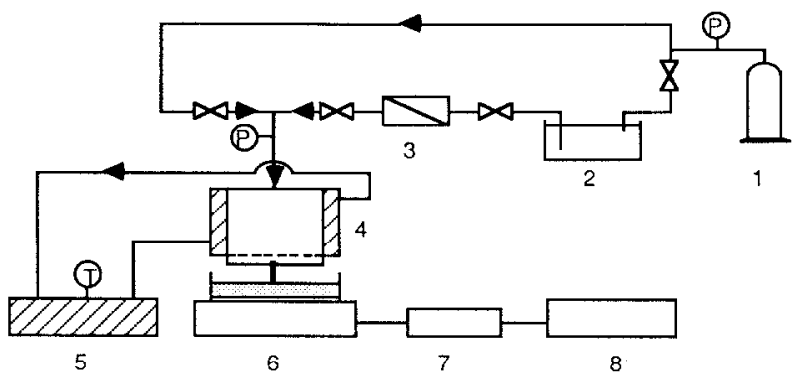

Fig. 3. The dead-end ultrafiltration equipment. (1) Technical air; (2) Pressure vessel; (3) Prefilter; (4) Ultrafiltration cell; (5) Thermostat bath; (6) Balance; (7) D/A converter; (8) Recorder. 
tention, the protein concentration of the feed, the retentate and the permeate solutions was measured spectrophotometrically.

\section{Results and discussion}

In the calculations that follow and in the simulation computer program, some properties of BSA solutions will be used: the partial specific volume, the sedimentation coefficient and the diffusion coefficient. The values used for the partial specific volume are $v_{1}=1 /\left(1.34 \cdot 10^{3}\right)=0.75 \cdot 10^{-3} \mathrm{~m}^{3} / \mathrm{kg}$ [5] and $v_{0}=1.0 \cdot 10^{-3} \mathrm{~m}^{3} / \mathrm{kg}$. The values for the concentration dependent sedimentation coefficient were determined experimentally (Results, Section A). Some measurements were also performed to determine the diffusion coefficient of BSA at high concentrations (Results, Section B).

\section{A. The sedimentation coefficient}

The sedimentation coefficients of BSA had to be measured because of the very limited amount of literature data on these coefficients. These coefficients were largely determined at very low concentrations or a different $\mathrm{pH}$, whereas for our model knowledge of the sedimentation coefficients over a large concentration range is needed. The coefficients as determined at $\mathrm{pH} 7.4$ and $I=0.125$ $N$, at $20^{\circ} \mathrm{C}$, are given in Fig. 4. The dependence on the concentration can best be described by

$1 / s=\left(1 / 4.412 \cdot 10^{-13}\right) \cdot\left(1+7.051 \cdot 10^{-3} C+3.002 \cdot 10^{-5} C^{2}+1.173 \cdot 10^{-7} C^{3}\right)$

The line in Fig. 4 is drawn according to eqn. 14. A comparison of literature

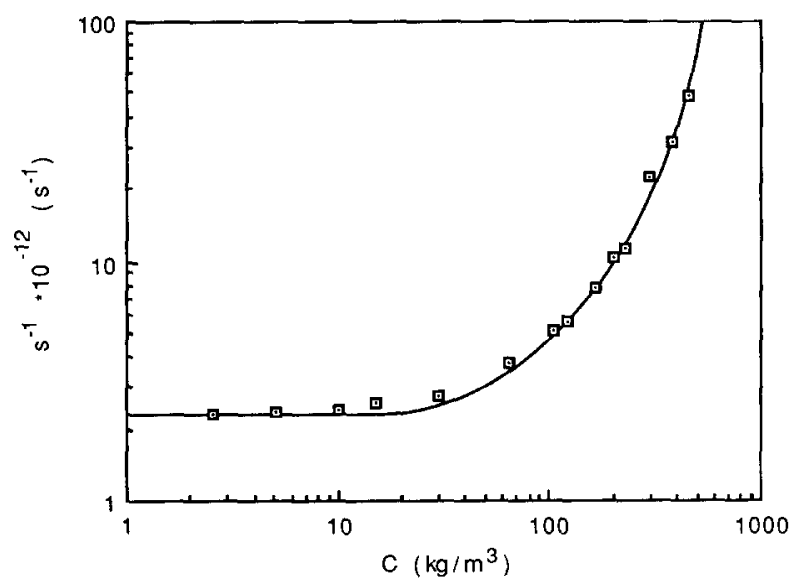

Fig. 4. The (apparent, reciprocal) sedimentation coefficient of BSA as a function of concentration ( $\mathrm{pH}=7.4, I=0.125 \mathrm{~N}$ and $T=20^{\circ} \mathrm{C}$ ). 
data with our consistent measurements is difficult: Kitchen et al. [13] found a qualitatively similar dependence on the concentration up to $80 \mathrm{~kg} / \mathrm{m}^{3}$ starting at $\left(s_{20, \mathrm{w}}\right)_{0}=4.1 \cdot 10^{-13} \mathrm{sec}$; for unbuffered BSA solutions, according to Anderson et al. [14] the value of the $\mathrm{pH}$ will be around 6.5 at that point. The value found by Cohn et al. [15] is $s(1 \%)=4.0 \cdot 10^{-13} \mathrm{sec}$, measured at $\mathrm{pH}$ 7.7. Our value of $4.12 \cdot 10^{-13} \mathrm{sec}$ for $s\left(10 \mathrm{~kg} / \mathrm{m}^{3}\right)$ at $\mathrm{pH} 7.4$ is in good agreement with this literature value.

\section{B. The diffusion coefficient}

The data on the diffusion coefficient of BSA at $\mathrm{pH} 7.4$ at high concentrations are limited: in the literature on modelling concentration polarization during ultrafiltration, constant values are used for high concentrations. Trettin and Doshi [9] use $D=6.91 \cdot 10^{-11} \mathrm{~m}^{2} / \mathrm{sec}$, a value which was originally determined at a low concentration. Shen and Probstein [16] use $D=6.7 \cdot 10^{-11} \mathrm{~m}^{2} / \mathrm{sec}$, a value which was derived from ultrafiltration experiments and represents the diffusion coefficient at the "gel concentration" of $580 \mathrm{~kg} / \mathrm{m}^{3}$. We determined the value of the diffusion coefficient up to $210 \mathrm{~kg} / \mathrm{m}^{3}$. In Fig. 5 our data are compared to those obtained by several other authors:

1. Phillies et al. [17]: these data were determined at $\mathrm{pH} 7.2$ to 7.5 ;

2. Anderson et al. [14]: data at $\mathrm{pH} 6.5$; their equation $D=5.9$ $10^{-11} \cdot\left(1+6 \cdot 10^{-4} \cdot C\right)$ was extrapolated to higher concentrations;

3. Fair et al. [18] obtained data at $\mathrm{pH} 7.4$;

4. Van Damme et al. [19] obtained data at $\mathrm{pH} 7.2$ up to $327 \mathrm{~kg} / \mathrm{m}^{3}$; and finally

5. Kitchen et al. [13] used unbuffered BSA solutions up to $240 \mathrm{~kg} / \mathrm{m}^{3}$. All solutions mentioned had an ionic strength of at least $0.1 \mathrm{~N}$. This extensive review of data on diffusion coefficients of BSA at $\mathrm{pH}$ values around 7.4 and at

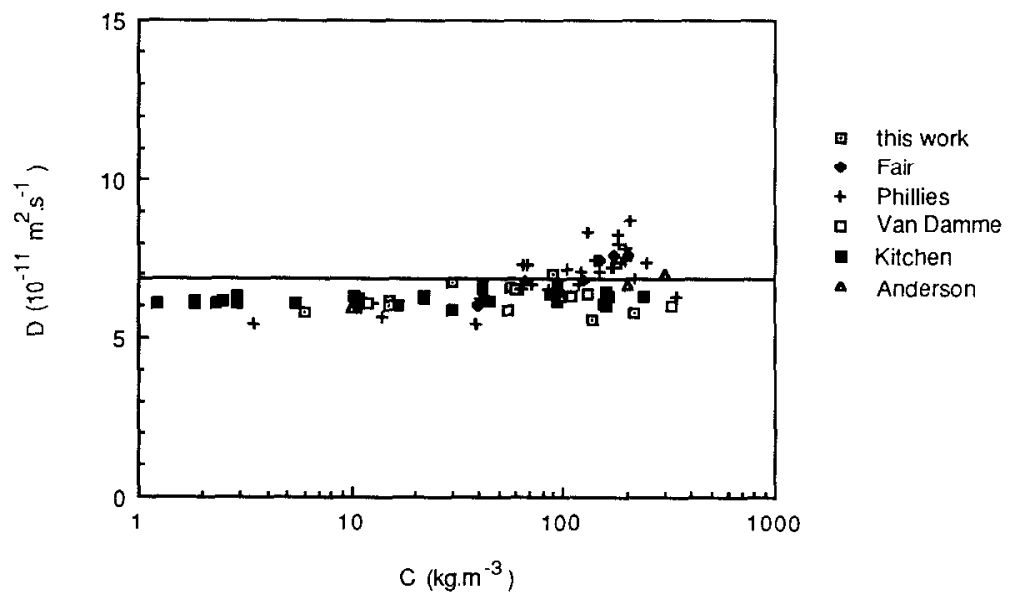

Fig. 5. The diffusion coefficient of BSA as a function of concentration, data from several authors, $-: D=6.9 \cdot 10^{-11} \mathrm{~m}^{2} / \mathrm{sec}$. 
moderate to high concentrations shows that the diffusion coefficient does not significantly depend on the concentration of the solution. In our calculations we used $D=6.9 \cdot 10^{-11} \mathrm{~m}^{2} / \mathrm{sec}$ over the entire range of concentrations. In the last part of Section D, the sensitivity of the model to the value of the diffusion coefficient will be discussed.

C. The flux behaviour during dead-end ultrafiltration: analysis using the "cake filtration" model

The results of some typical dead-end ultrafiltration experiments are given in Figs. 6 and 7, obtained by plotting the reciprocal flux $\left(1 / J_{\mathrm{v}}\right)$ as a function of the specific cumulative permeate volume $\left(V_{\mathrm{p}} / A\right)$. In Fig. 6 the dependence on the concentration is shown at constant pressure, while in Fig. 7 the concentration is constant and the pressure varies. A linear relation exists in all cases, where the $1 / J_{\mathrm{v}}$ value at $V_{\mathrm{p}} / A=0$ represents the reciprocal clean water flux. This clean water flux varied only slightly before and after the experiment, i.e. 0-5\% decline for the YM-30 membrane; for the PM-30 membrane only those experiments were used where the flux decline was less than $10 \%$. This very small effect of adsorption or pore blocking on a YM-30 membrane was also observed by Reihanian et al. [20].

The linear relationship between the reciprocal flux and the cumulative permeate volume is a well known phenomenon in unstirred dead-end ultrafiltration; however, it is better known as the $V_{\mathrm{p}} \sim t^{0.5}$ relationship. This relationship can be derived easily from the boundary layer theory: eqn. (6) simplifies to eqn. (15) when the resistance of the membrane is neglected compared to the resistance of the concentrated layer:

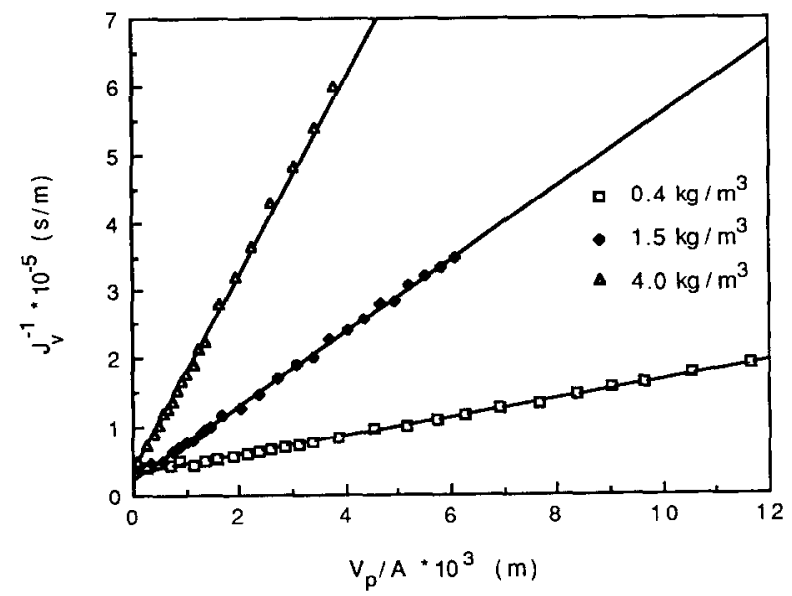

Fig. 6. The reciprocal flux as a function of the specific cumulative permeate volume at different concentrations (ultrafiltration of BSA at $\Delta P=1.0 \cdot 10^{5} \mathrm{~Pa}, \mathrm{YM}-30$ membrane). 


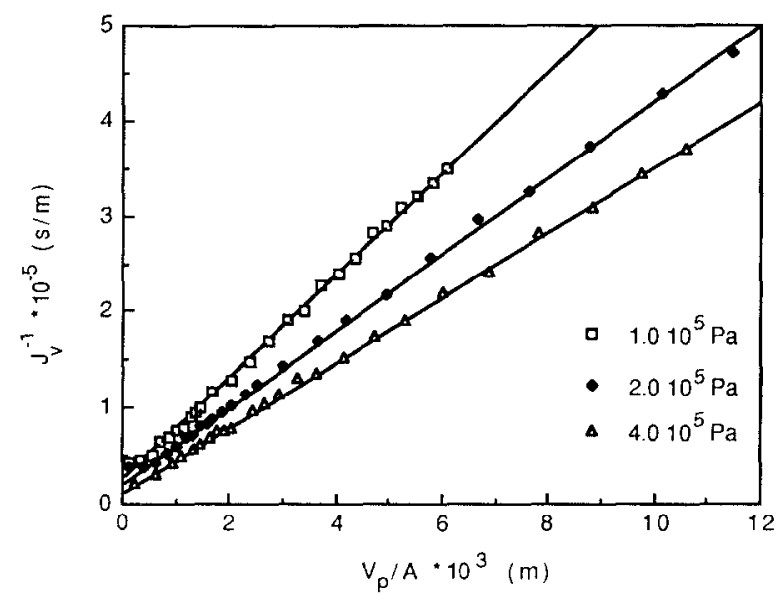

Fig. 7. The reciprocal flux as a function of the specific cumulative permeate volume at different applied pressures (ultrafiltration of BSA with $C_{\mathrm{b}}=1.5 \mathrm{~kg} / \mathrm{m}^{3}$, YM-30 membrane).

$1 / J_{\mathrm{v}}=\mathrm{d} l / \mathrm{d}\left(V_{\mathrm{p}} / A\right)=\left(\eta_{0} \cdot C_{\mathrm{b}} \cdot R_{\mathrm{obs}} / \Delta P\right) \cdot\left(r_{\mathrm{bl}} / C_{\mathrm{bl}}\right) \cdot\left(V_{\mathrm{p}} / A\right)$

from which the time-permeate volume relationship can be derived by integration:

$t=\left(\eta_{0} \cdot C_{\mathrm{b}} \cdot R_{\mathrm{obs}} / 2 \cdot \Delta P\right) \cdot\left(r_{\mathrm{bl}} / C_{\mathrm{bl}}\right) \cdot\left(V_{\mathrm{p}} / A\right)^{2}$

This $V_{\mathrm{p}} \sim t^{0.5}$ dependence is also found by Vilker et al. [5], Trettin and Doshi [9], Reihanian et al. [20] and Chudacek and Fane [21], each using a different theory.

A strong dependence of the reciprocal flux on both the concentration and the applied pressure is obvious from the slopes of the various lines. The flux decline indices $r_{\mathrm{bl}} / C_{\mathrm{bl}}$ are calculated from these slopes according to eqn. (7). In Fig. 8, $r_{\mathrm{bl}} / C_{\mathrm{bl}}$ is plotted as a function of the bulk concentration for both the YM-30 membrane and the PM-30 membrane. The results show that the flux decline index tends to reach a constant value for higher concentrations, at each applied pressure, after a slight increase at concentrations below $2 \mathrm{~kg} / \mathrm{m}^{3}$.

From the figure it may be concluded that the build-up of a concentrated "cake" layer near the membrane surface as obtained by analysis of the experimental data yields the same result for different membranes. However, these results are a little different from those of Nakao [1], who found only a linear dependence on the concentration. Nakao performed experiments with dextrans and polyethylene glycols only at low concentrations (less than $0.6 \mathrm{~kg} /$ $\left.\mathrm{m}^{3}\right)$. The influence of the retention, which was $95 \%$ or more in our case, is included in the calculations, as represented by eqn. (7). Taking the plateau value of $r_{\mathrm{b} 1} / C_{\mathrm{bl}}$ at each pressure, the influence of the applied pressure on these values is given in Fig. 9. 


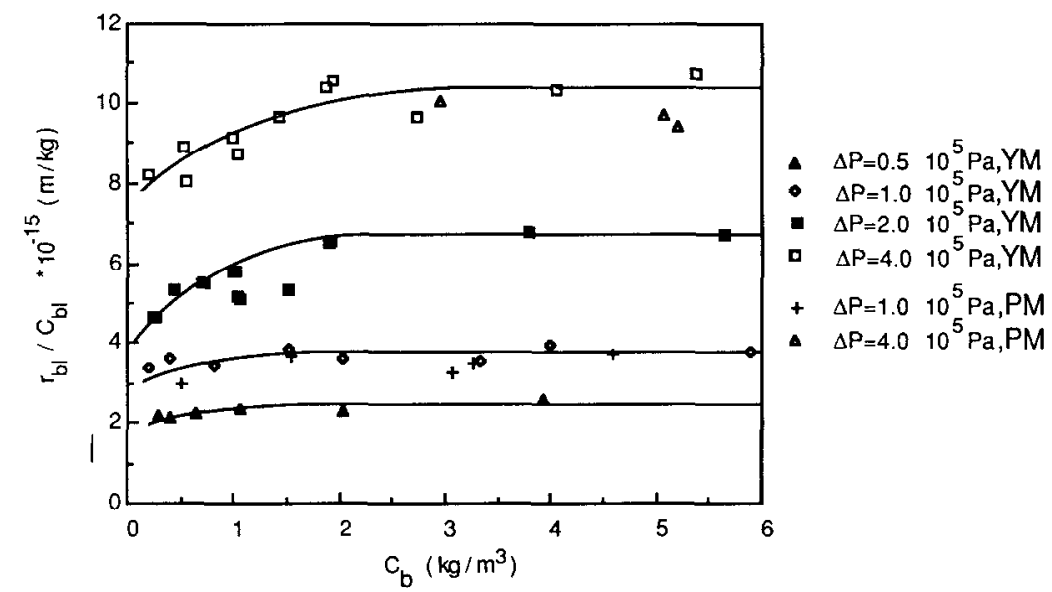

Fig. 8. The flux decline index $r_{\mathrm{bl}} / C_{\mathrm{bl}}$ as a function of concentration at several applied pressures (YM-30 and PM-30 membranes used).

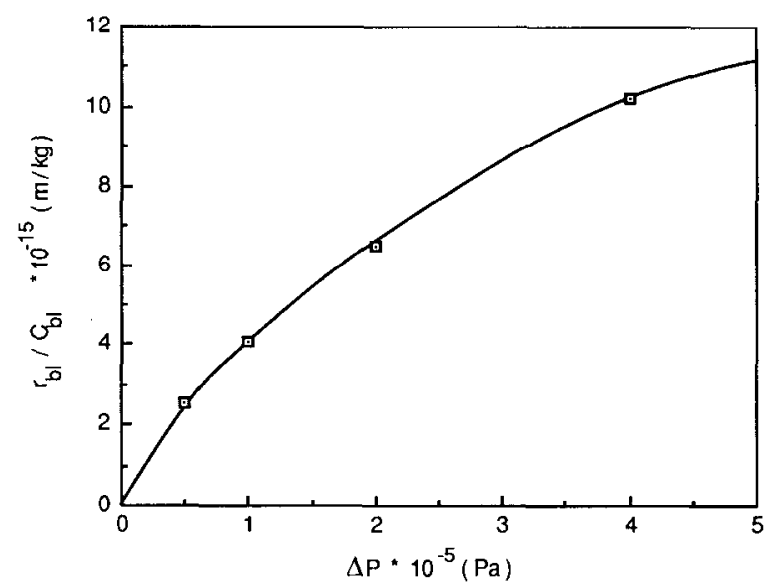

Fig. 9. The plateau values of the flux decline index $r_{\mathrm{ul}} / C_{\mathrm{bl}}$ as a function of the applied pressure.

From the $r_{\mathrm{bl}} / C_{\mathrm{bl}}$ values the "cake" concentrations in the boundary layer $C_{\mathrm{bl}}$ can be calculated via the $s\left(C_{\mathrm{bl}}\right)$ values by using eqn. (8) and eqn. (14). 'The resulting boundary layer concentrations are given in Fig. 10 as a function of the initial concentration of the bulk and the applied pressure.

As for the flux decline index, a plateau value for the boundary layer "cake" concentration also appears here, although the influence of the concentration of the bulk is not as clear as it was for the $r_{\mathrm{bl}} / C_{\mathrm{bl}}$ values. The calculated $C_{\mathrm{bl}}$ concentrations, which vary from 180 to $440 \mathrm{~kg} / \mathrm{m}^{3}$, are all smaller than the gel concentration of $585 \mathrm{~kg} / \mathrm{m}^{3}$ which was obtained for BSA at $\mathrm{pH} 7.4$ (in fact a 


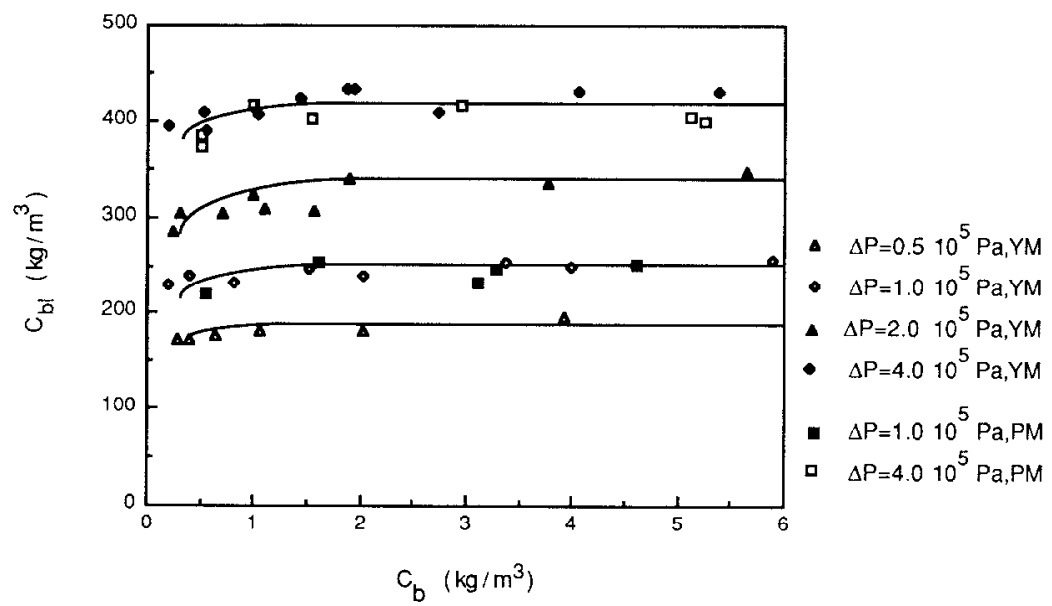

Fig. 10. The calculated boundary layer concentration $C_{\mathrm{bl}}$ as a function of the initial bulk concentration and the applied pressure.

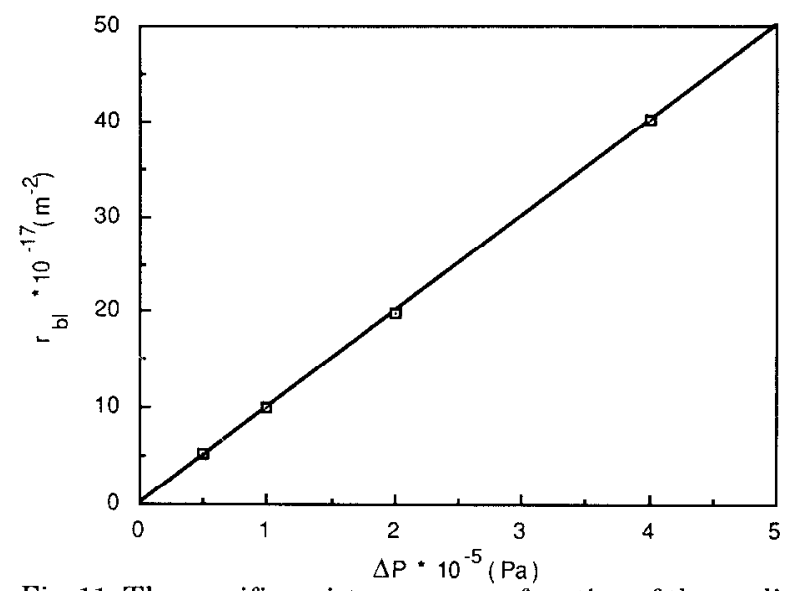

Fig. 11. The specific resistance $r_{\mathrm{b} 1}$ as a function of the applied pressure.

solubility limit was determined) [22]. According to this gel concentration and the model used no gelation will occur at this stage in the boundary layer.

Knowing the $r_{\mathrm{bl}} / C_{\mathrm{bl}}$ values and the $C_{\mathrm{bl}}$ values at the various applied pressures, the values of the specific resistance $r_{\mathrm{hl}}$ can be calculated easily, and the results are given in Fig. 11. From these experimental data it is clear that the specific resistance is linearly dependent on the applied pressure as given in eqn. (17). The dependence of the boundary layer concentration on the applied pressure is given in eqn. (18), from which the dependence of the flux decline index on the applied pressure can be calculated eqn. (19). 
$r_{\mathrm{b} 1}=9.9 \cdot 10^{17}\left(10^{-5} \Lambda P\right)=9.9 \cdot 10^{12} \Delta P$

$C_{\mathrm{bl}}=260\left(10^{-5} \cdot \Delta P\right)^{\frac{1}{3}}=5.60(\Delta P)^{\frac{1}{3}}$

$r_{\mathrm{bl}} / C_{\mathrm{bl}}=3.8 \cdot 10^{15}\left(10^{-5} \cdot \Delta P\right)^{\frac{2}{3}}=1.76 \cdot 10^{12}(\Delta P)^{\frac{2}{3}}$

The dependence of $r_{\mathrm{bl}}$ and $\delta$ (via $C_{\mathrm{bl}}$ ) on $\Delta P$ results in boundary layer resistance values $\left(R_{\mathrm{bl}}\right)$ which are proportional to $\Delta P^{\frac{2}{3}}$. This result indicates directly that the flux $J_{\mathrm{v}}=\Delta P /\left[\eta_{0} \cdot\left(R_{\mathrm{m}}+R_{\mathrm{bl}}\right)\right]$ is not linearly dependent on $\Delta P$, as is commonly known. In fact the flux is proportional to $\Delta P^{\frac{1}{3}}$ at equal cumulative permeate volumes $V_{\mathrm{p}}$ for the case where the membrane resistance can be neglected.

Other concentration polarization models concerning dead-end ultrafiltration have also led to values for the specific resistance of the layer near the membrane, sometimes as a function of the applied pressure. Unfortunately a different meaning is sometimes given to the term specific resistance; however, by analysing the dimensions of the quantities given a comparison can be made:

Reihanian et al. [20] determined gel layer permeabilities, using $C_{\mathrm{bl}}=C_{\mathrm{g}}=590$ $\mathrm{kg} / \mathrm{m}^{3}$ (BSA at $\mathrm{pH} 7.4$ ), resulting in $r_{\mathrm{bl}}=6.7-33 \cdot 10^{17} \mathrm{~m}^{-2}$.

Chudacek and Fane [21], using BSA at pH 7.4 and $C_{\mathrm{g}}$ values of $30-40 \%$, found values of $r_{\mathrm{bl}} / C_{\mathrm{bl}}$ depending strongly on the applied pressure and also slightly on the concentration. The values for $2 \mathrm{~kg} / \mathrm{m}^{3}$ can be represented by $r_{\mathrm{bl}} / C_{\mathrm{bl}} \approx 4.0 \cdot 10^{15}\left(10^{-5} \Delta P\right)^{0.55}$, which is in fair agreement with eqn. (19).

Finally, Dejmek [23], after many experiments at various $\mathrm{pH}$ values, found a relation which was independent of the $\mathrm{pH}$ value and which described the dependence of his "specific resistance" of the gel layer (with dimension sec ${ }^{-1}$ ) on the pressure by $(\Delta P)^{0.72}$. Recalculation of his data showed that he calculated a quantity equivalent to our $r_{\mathrm{bl}} / C_{\mathrm{bl}}$ values, apart from a constant factor, which result is also in rather good agreement with eqn. (19).

\section{The new approach of the boundary layer resistance dead-end ultrafiltration model}

Before comparing the results of the analysis of experimental data according to Nakao's dead-end ultrafiltration model and the results of the computer simulations, it will be shown that the computer simulations indeed agree with the experimental data. In Fig. 12 the data of two different experiments are compared with the data as calculated by the computer. For one experiment the initial concentration is $2.032 \mathrm{~kg} / \mathrm{m}^{3}$ and $\Delta P=1.0 \cdot 10^{5} \mathrm{~Pa}$, while for the other experiment the initial concentration is $1.423 \mathrm{~kg} / \mathrm{m}^{3}$ and $\Delta P=4.0 \cdot 10^{5} \mathrm{~Pa}$. From both comparisons it may be concluded that the simulations approximate the experimental results very well. Despite the different initial concentrations, different retentions and resistances of the membrane and, especially, the different applied pressures, the difference between the experimental and the simulation data is smaller than $5 \%$. This same result was obtained for a large 


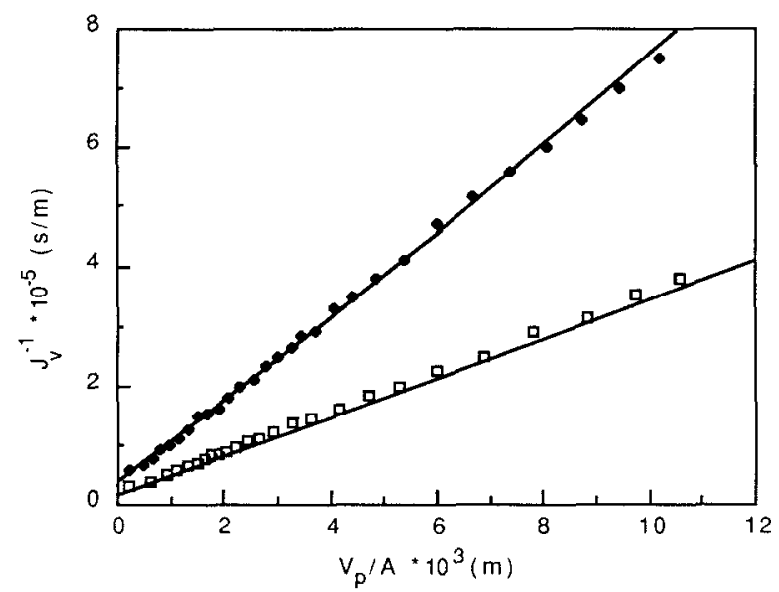

Fig. 12. Comparison between reciprocal flux data obtained from ultrafiltration experiments and the computer simulation of these experiments. Simulation: -; experiments: $\Delta P=1.0 \cdot 10^{5} \mathrm{~Pa}$, $R_{\mathrm{m}}=2.78 \cdot 10^{12} \mathrm{~m}^{-1}, R_{\mathrm{tbs}}=0.977, C_{\mathrm{b}}=0.994 \mathrm{~kg} / \mathrm{m}^{3} \square: \Delta P=4.0 \cdot 10^{5} \mathrm{~Pa}, R_{\mathrm{m}}=4.55 \cdot 10^{12} \mathrm{~m}^{-1}$, $R_{\mathrm{ulk}}=1.0, C_{\mathrm{k}}=1.423 \mathrm{~kg} / \mathrm{m}^{3}$.

number of experiments. It is characteristic of the simulations that the slope of the "straight" line approaches the experimental slopes very well, whereas at the first part of the simulated line a small non-linear section exists. Depending on the resistance of the membrane and the applied pressure, the reciprocal flux is initially less than linear with the specific cumulative permeate volume. This can be observed especially when large membrane resistances and/or small applied pressures are used, and it indicates that the simulation of the first few seconds underpredicts the resistance build-up. Probably this is a result of the initial pore obstruction, and the resulting increase in the effective $R_{\mathrm{m}}$ value, during an experiment.

\section{Some results derived from the simulations}

During the simulations of the experiments it is possible to show the concentration profile near the membrane at every desired moment. For a number of time intervals this has been done to obtain an impression of the development of the profile with time (Fig. 13). A number of characteristic phenomena (valid for all simulations) can be observed, as follows.

(a) Even after a very short time interval, high concentrations are reached at the membrane interface: $C_{\mathrm{m}} \approx 260 \mathrm{~kg} / \mathrm{m}^{3}$ after $10 \mathrm{sec}$ in Fig. 13 , while the initial concentration was $4.0 \mathrm{~kg} / \mathrm{m}^{3}$. The thickness of the layer $\delta$ built up after $10 \mathrm{sec}$ is very small: $\delta \approx 20 \mu \mathrm{m}$.

(b) The concentration at the membrane interface continues to increase: 350 


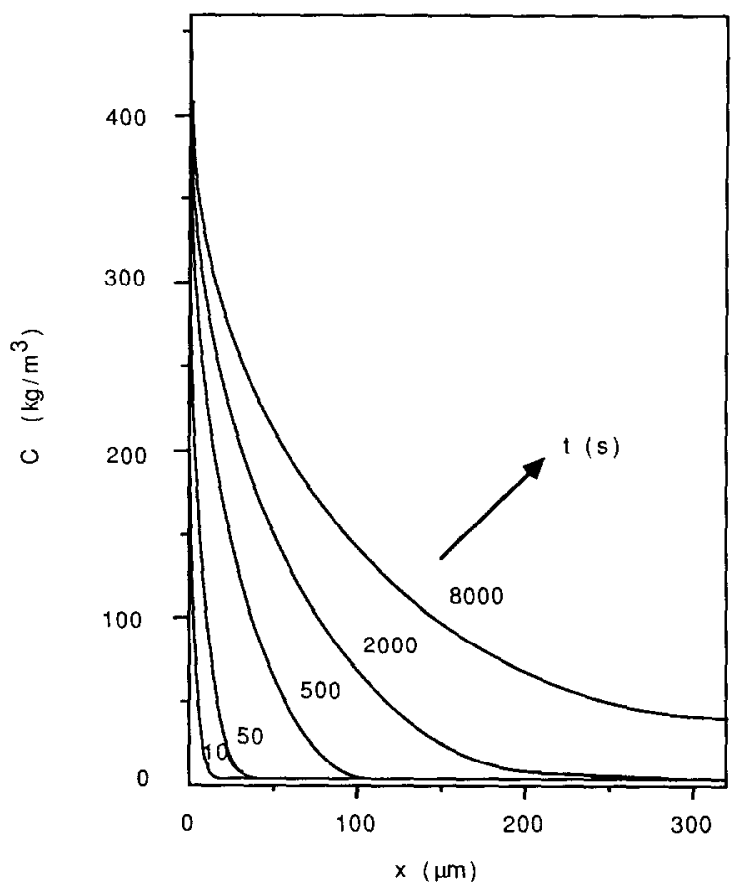

Fig. 13. Simulated concentration profiles near the membrane interface as a function of time and distance from the membrane $\left(\Delta P=1.0 \cdot 10^{5} \mathrm{~Pa}, R_{\mathrm{m}}=3.76 \cdot 10^{12} \mathrm{~m}^{-1}, R_{\mathrm{obs}}=1.0, C_{\mathrm{b}}=4.00 \mathrm{~kg} / \mathrm{m}^{3}\right)$.

$\mathrm{kg} / \mathrm{m}^{3}$ after $50 \mathrm{sec}$ up to $385 \mathrm{~kg} / \mathrm{m}^{3}$ after $500 \mathrm{sec}$, and the thickness $\delta$ increases clearly ( $\delta \approx 120 \mu \mathrm{m}$ after $500 \mathrm{sec}$ ).

(c) At longer times the concentration at the membrane interface reaches a plateau value, which is different for each applied pressure, and which is approximately $405 \mathrm{~kg} / \mathrm{m}^{3}$ for $\Delta P=1.0 \cdot 10^{5} \mathrm{~Pa}$. In Fig. 14 the increase of the concentration at the membrane interface is plotted as a function of time.

(d) Having reached the stationary-state concentration at the membrane interface, the concentration profile only expands away from the membrane. This expansion will proceed more and more slowly in time because of the decreased supply of the solute through diminished flux values.

The stationary state concentration at the membrane interface mentioned under point (c) appears to be highly dependent on the applied pressure (Fig. $15)$. From this figure it is clear that the concentration at the membrane interface first increases strongly with increasing pressure, but later the dependence on the pressure decreases. The calculated concentrations increase up to values larger than the generally known gel concentration of $585 \mathrm{~kg} / \mathrm{m}^{3}$ for BSA at $\mathrm{pH}$ 7.4. This gel concentration value is reached at $\Delta P \approx 3.0 \cdot 10^{5} \mathrm{~Pa}$. However, despite these extremely high concentrations, the calculated flux behaviour accords well with the experiments. 


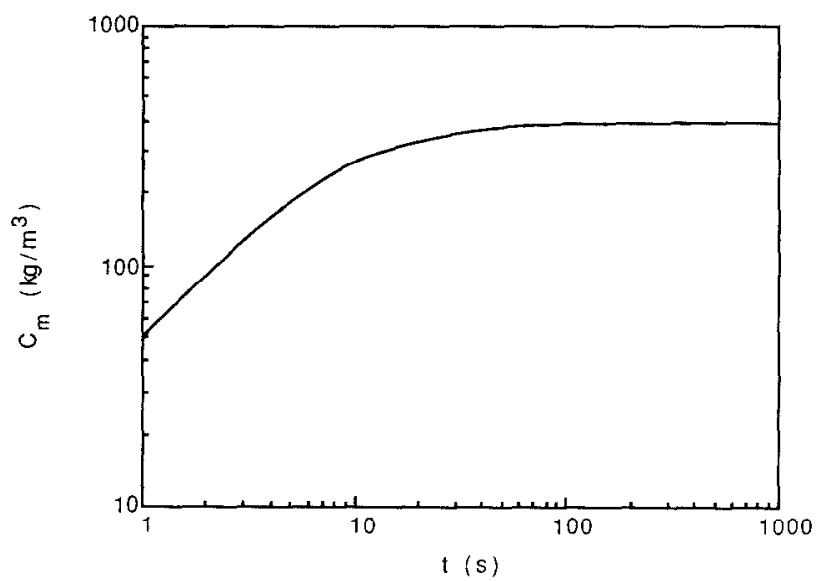

Fig. 14. The concentration at the membrane interface as a function of time. (Data obtained by simulation: $\left.\Delta P=1.0 \cdot 10^{i} \mathrm{~Pa}, R_{\mathrm{m}}=3.76 \cdot 10^{1.2} \mathrm{~m}^{-1}, R_{\mathrm{ibs}}=1.0, C_{\mathrm{b}}=4.00 \mathrm{~kg} / \mathrm{m}^{3}\right)$.

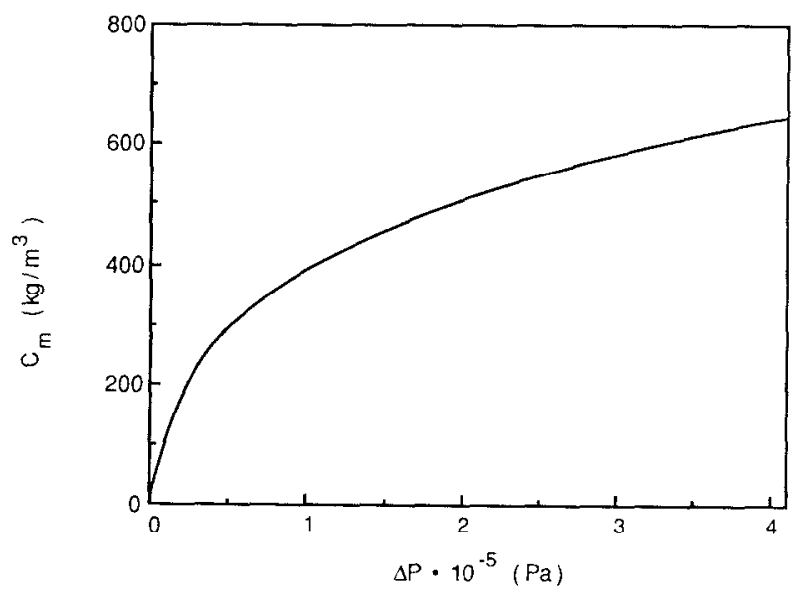

Fig. 15. The stationary state concentration at the membrane interface as a function of the applied pressure. (Data obtained by simulation: $R_{t, 1}=4.0 \cdot 10^{12} \mathrm{~m}^{-1}, R_{\mathrm{t}, \mathrm{ts}}=1.0, C_{1}=1.0 \mathrm{~kg} / \mathrm{m}^{33}$ ).

Comparison of the results obtained from computer simulations and from the analysis of the experimental data by Nakao's model

The comparison between the two versions of the boundary layer resistance model for dead-end ultrafiltration of $\mathrm{BSA}$ at $\mathrm{pH} 7.4$ is possible by comparing the slope $\alpha$, which is proportional to the flux decline, and which is defined by $\alpha=\mathrm{d}\left(1 / J_{\mathrm{v}}\right) / \mathrm{d}\left(V_{\mathrm{p}} / A\right)$

According to Nakao et al. this slope is given by eqn. (7)

$\alpha=\left(\eta_{0} \cdot C_{\mathrm{b}} \cdot R_{\mathrm{obs}} / \Delta P\right) \cdot\left(r_{\mathrm{bl}} / C_{\mathrm{bl}}\right)$ 
In the case of the simulations, the slope of the straight part of the line is calculated from the data between $V_{\mathrm{p}} / A$ values of $5 \cdot 10^{-3}$ and $10^{-2} \mathrm{~m}$ (compare Fig. 12).

\section{The influence of the initial bulk concentration}

Both for the experimental and the computer-simulated data, an initial increase in the $\alpha \cdot \Delta P / C_{\mathrm{b}}$ value $\left[=\left(r_{\mathrm{bl}} / C_{\mathrm{bl}}\right) \cdot R_{\mathrm{obs}} \cdot \eta_{0}\right]$ can be observed with increasing bulk concentration, starting from $\alpha \cdot \Delta P / C_{\mathrm{b}}=0$ at $C_{\mathrm{b}}=0$ for the simulated data (Fig. 16). This starting value seems very reasonably, as in the absence of solute no extra resistance or concentrated layer can be formed. When the bulk concentration is still very low, the equilibrium concentration at the membrane interface also reaches rather small values, resulting in relatively small $\alpha \cdot \Delta P / C_{\mathrm{b}}$ or $r_{\mathrm{bl}} / C_{\mathrm{bl}}$ values. After the initial increase, the $\alpha \cdot \Delta P / C_{\mathrm{b}}$ values reach a plateau. Unlike these simulated results and those of experimentals, it follows from Nakao's model (eqn. 7) that $\alpha$ is proportional to $C_{\mathrm{b}}$, which was valid only for higher concentrations. As shown above, the new model can predict this phenomenon correctly.

\section{The influence of the observed retention}

According to Nakao's model, $\alpha$ is proportional to the observed retention. This could not be confirmed or disproved by experimental data because the retention values were larger than $95 \%$ and thus had too little influence. From the simulations it followed that the slope $\alpha$ is indeed proportional to the retention (Fig. 17).

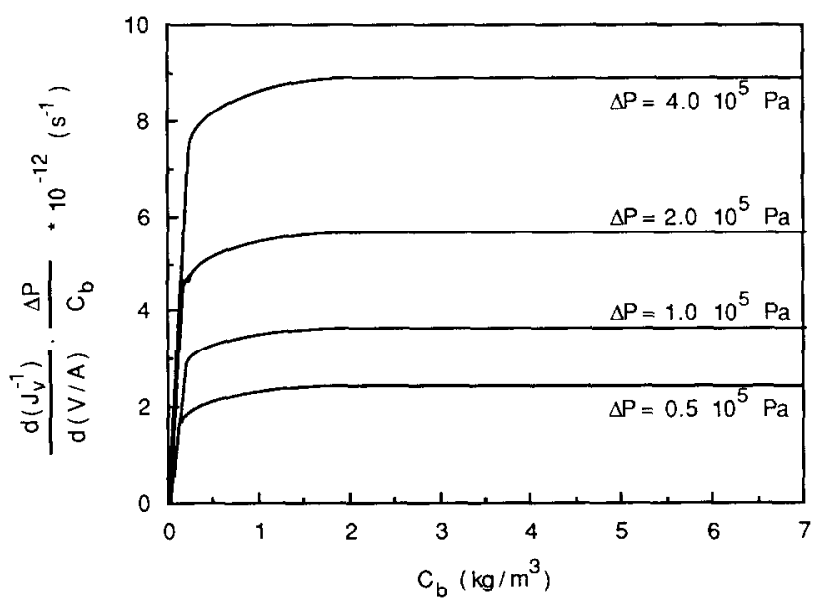

Fig. 16. The influence of the initial bulk concentration on the calculated value of $\alpha \cdot \Delta P / C_{\mathrm{b}}$. (Data obtained by simulation: $\Delta P=(0.5,1,2$ or 4$\left.) \cdot 10^{5} \mathrm{~Pa}, R_{\mathrm{m}}=4.0 \cdot 10^{12} \mathrm{~m}^{-1}, R_{\mathrm{obs}}=1.0\right)$. 


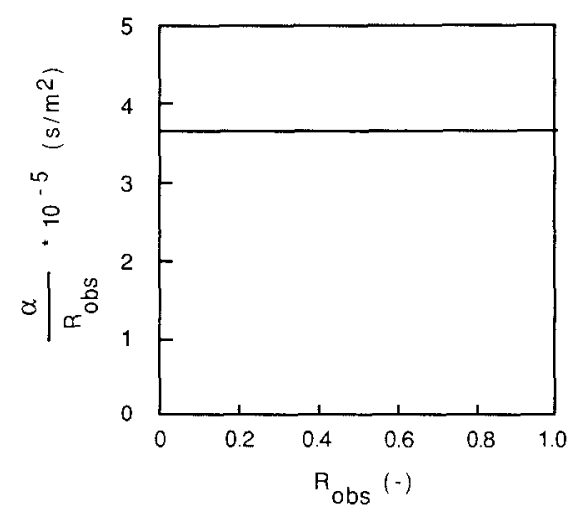

Fig. 17.The influence of the retention on the $\alpha / R_{\mathrm{olbs}}$ value. (Data obtained by simulation: $\Delta P=1.0 \cdot 1.10^{5} \mathrm{~Pa}, R_{\mathrm{m}}=4.0 \cdot 10^{12} \mathrm{~m}^{-1}$ ).

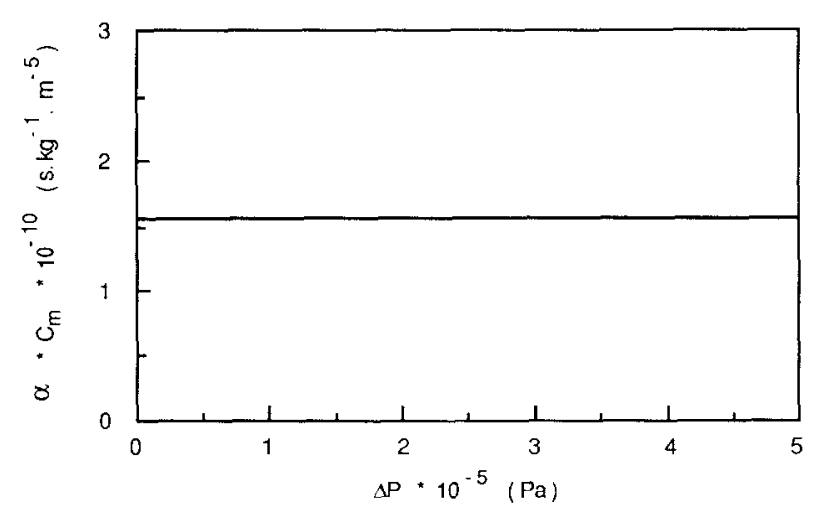

Fig. 18. The influence of the applied pressure on the $\alpha \cdot C_{\mathrm{m}}$ value. (Data obtained by simulation: $\left.R_{\mathrm{m}}=4.0 \cdot 10^{12} \mathrm{~m}^{-1}, R_{\text {t: hs }}=1.0, C_{\mathrm{b}}=1.00 \mathrm{~kg} / \mathrm{m}^{3}\right)$.

The influence of the applied pressure

It is difficult to describe directly the influence of the applied pressure in the new version of the model, owing to the absence of such terms as $C_{\mathrm{bl}}$ and $r_{\mathrm{bl}}$. However, it followed from the analysis of the experimental data by Nakao's model that $r_{\mathrm{bl}}=k \cdot \wedge P$ (Fig. 11), from which it can be deduced that $\alpha \cdot C_{\mathrm{bl}}$ is a constant for one set of $R_{\mathrm{obs}}$ and $C_{\mathrm{b}}$ values, since $\alpha \cdot C_{\mathrm{bl}}=\left(\eta_{0} \cdot C_{\mathrm{b}} \cdot R_{\mathrm{obs}}\right)$ $\Delta P) \cdot(k \cdot \Delta P)$, which is proportional to $k$. So $\alpha$ is proportional to $1 / C_{\mathrm{bl}}$.

The data from the simulations of experiments at various pressures showed that $\alpha$ is also proportional to $1 / C_{\mathrm{m}}\left(\alpha \cdot C_{\mathrm{m}}\right.$ is a constant in Fig. $18, C_{\mathrm{m}}$ being the concentration at the membrane interface in a stationary-state situation). Furthermore, it may be concluded that $C_{\mathrm{m}}$ is only dependent on the pressure, which follows from all simulations with different parameters.

As mentioned before, the dependence of $C_{\mathrm{h} 1}$ on $\Delta P$, according to Nakao's 
model, can be described as $C_{\mathrm{bl}} \approx 260\left(10^{-5} \Delta P\right)^{\frac{1}{3}}$. According to the computer simulations, this dependence is $C_{\mathrm{m}} \approx 405\left(10^{-5} \Delta P\right)^{\frac{1}{3}}$. Apart from the constant factor, an identical dependence on the pressure emerges. The reason for this difference is simply the shape of the profile which is assumed for the case of the cake filtration type of description: the constant concentration in the boundary layer is an average of a relatively thin layer with a higher concentration (and a higher $C_{m}$ value) and a layer with a lower concentration.

The influence of the hydraulic resistance of the membrane

In contrast to real experiments, it is very simple to vary the hydraulic resistance of the membrane in a computer simulation while keeping the other parameters constant. Figure 19 shows the results of simulating two different ultrafiltration experiments, each using three different $R_{\mathrm{m}}$ values. The influence of the $R_{\mathrm{m}}$ values seems of minor importance. In particular the influence of the membrane is minimized when the resistance of the boundary layer increases as a result of more solute supply from the bulk, by increasing the pressure or the concentration.

The sensitivity of the model to the value of the diffusion coefficient

It was shown in Section B that the diffusion coefficient of BSA is almost constant over a large range of concentrations. At very high concentrations $\left(100 \mathrm{~kg} / \mathrm{m}^{3}\right.$ and above ) there appeared to be several experimental data which were not exactly constant but were in the range from $(5$ to 9$) \cdot 10^{-11} \mathrm{~m}^{2} / \mathrm{sec}$. Up to this point all the computer calculations were done using one constant

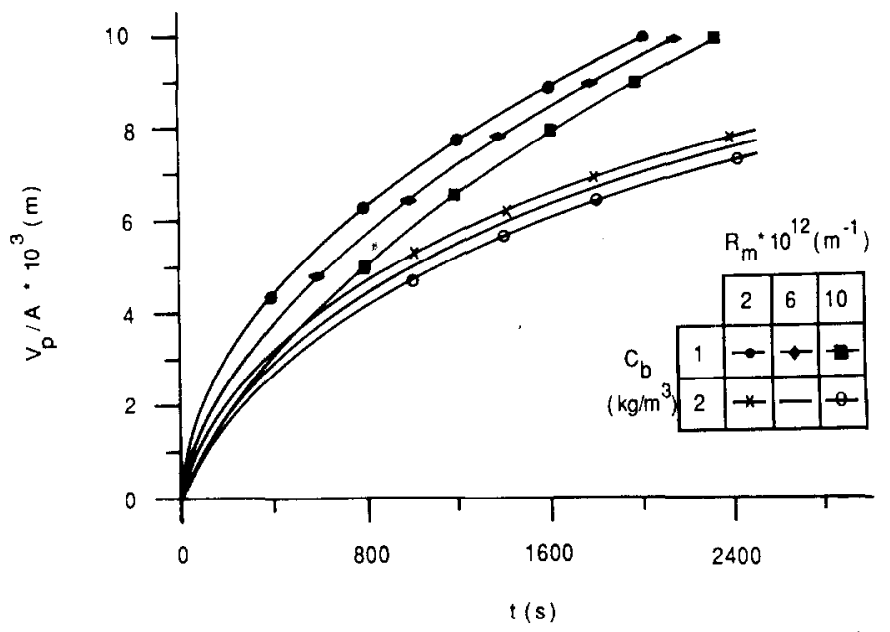

Fig. 19. The influence of the resistance of a membrane on the flux behaviour in two different situations. (Data points obtained by simulation: $C_{\mathrm{b}}=1 \mathrm{~kg} / \mathrm{m}^{33}$ and $C_{\mathrm{b}}=2 \mathrm{~kg} / \mathrm{m}^{3}, \Delta P=1.0 \cdot 10^{5} \mathrm{~Pa}$, $R_{0, \mathrm{ks}}=1.0$ ). 
value of the diffusion coefficient. In this part of the discussion, the influence of using a certain value will be demonstrated. By using values of the diffusion coefficient of $6 \cdot 10^{-12}$ to $2 \cdot 10^{-10} \mathrm{~m}^{2} / \mathrm{sec}$, the flux decline index and the concentration at the membrane interface were calculated, as well as the concentration profile near the membrane after filtration for $1000 \mathrm{sec}$. The other physico-chemical properties were kept constant during the simulations.

As can be felt intuitively, the concentration at the membrane will increase with decreasing values of the diffusion coefficient because of the decreased back-diffusion away from the concentrated phase. The concentrations increase when the diffusion coefficiont is very small, up to values as high as 800 $\mathrm{kg} / \mathrm{m}^{3}$ or even more ( $\mathrm{Fig} .20$ ), while the value of the concentration at the membrane interface is very dependent on the diffusion coefficient. On the other hand, when the diffusion coefficient is $5 \cdot 10^{-11} \mathrm{~m}^{2} / \mathrm{sec}$ or more, the concentration at the membrane interface appears to be much less dependent on the diffusion coefficient. The increased concentrations at the membrane interface at smaller diffusion coefficients also result in increased resistances of the concentrated layer (eqns. 8 and 14). And as can be expected from these equations the effect of the changing value of the diffusion coefficient is even more pronounced than in the case of the concentration at the membrane interface (Fig. 21 ). The relatively small effect of the change in diffusion coefficient in the region from $5 \cdot 10^{-11} \mathrm{~m}^{2} / \mathrm{sec}$ upwards shows that the exact value of the diffusion coefficient, within reasonabale limits, is of minor importance. Finally, the effect of the changing diffusion coefficient is also represented in the concentration profile after a certain filtration period. Figure 22 shows the concentration profiles after $1000 \mathrm{sec}$ in the case of six different diffusion coefficients. The increasing concentration with decreasing diffusion coefficient can be seen

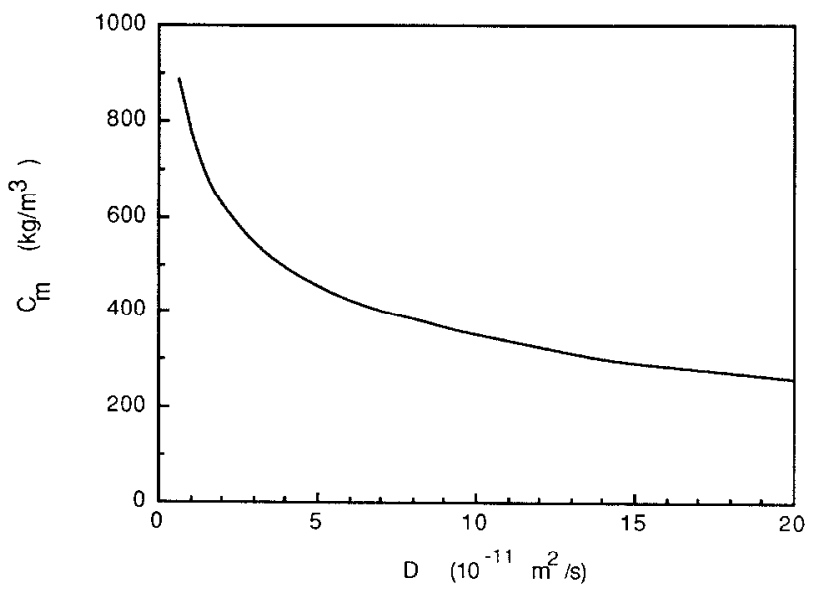

Fig. 20. The concentration at the membrane interface as a function of the diffusion coefficient, data obtained by simulation (conditions as in Fig. 13). 


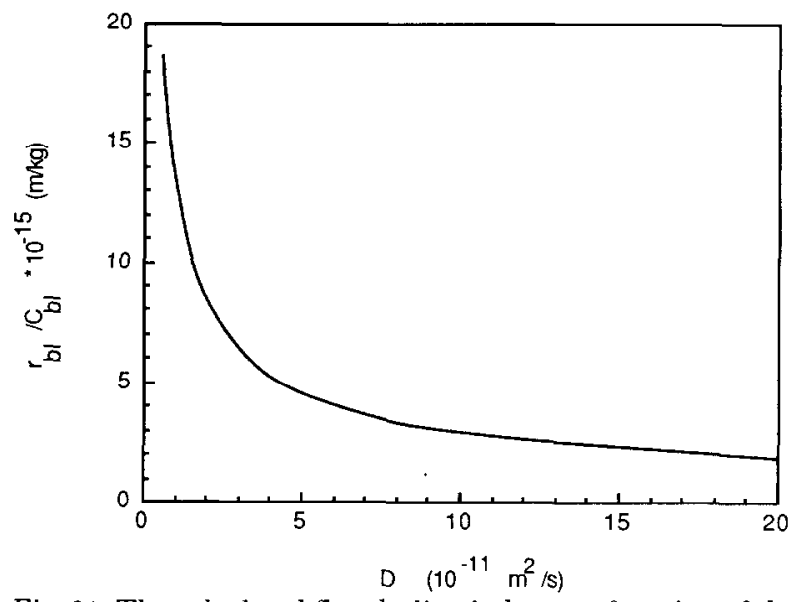

Fig. 21. The calculated flux decline index as a function of the diffusion coefficient, data obtained by simulation (conditions as in Fig. 13).

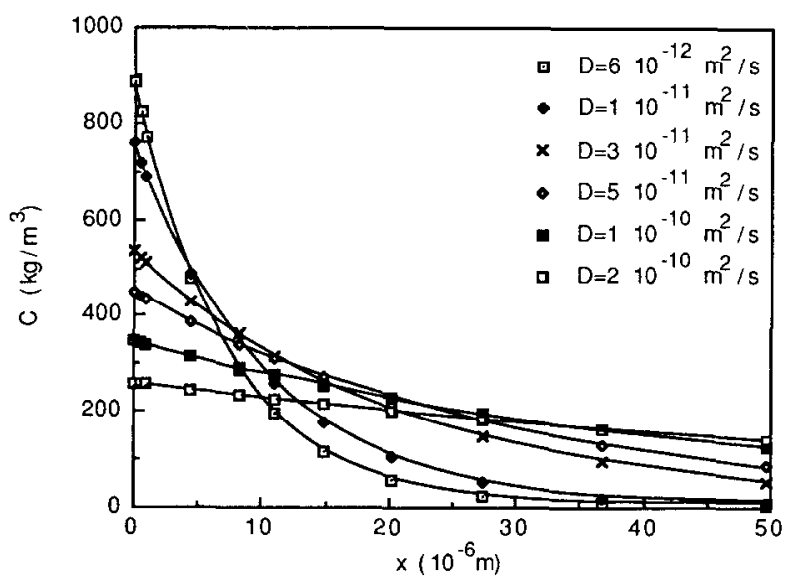

Fig. 22. The concentration profiles after 1000 seconds filtration using different values of the diffusion coefficient, data points obtained by simulation (conditions as in Fig. 13).

again as well as a very steep concentration gradient at small diffusion coefficients and a weak concentration gradient at larger diffusion coefficients. Although the amount of solute (equal to the surface under the graph and linearly related to the calculated cumulative permeate volume) increases with increasing diffusion coefficient, the flux decline index and the total resistance decrease. This is due to the concentration dependence of the sedimentation coefficient, needed in eqns. (8) and (14)

\section{Conclusions}

The use of the boundary layer resistance model principles in combination with a dynamic model, which describes the formation of a concentrated layer 
near the membrane interface, can predict the experimental flux behaviour very well. Analysis of the experimental dead-end ultrafiltration data for BSA at various conditions with Nakao's boundary layer resistance/cake filtration model yields relations concerning the dependence on the applied pressure that agree with literature values. In comparing our experimental data with those of Nakao et al., some deviations were found, probably because of the extended range of concentrations used in this study. The simulation of ultrafiltration experiments yielded a similar dependence on the applied pressure and the concentration as found by analysis with Nakao's model, but the calculated concentrations at the membrane reach extremely high values. Even so the predicted flux behaviour agrees with the experiments. These calculations also resulted in some interesting conclusions concerning the build-up of the concentrated layer near the membrane interface. Extended simulations showed a linear dependence of the flux decline index on the retention and only a limited influence of the hydraulic resistance of the membrane itself.

\section{Acknowledgements}

Thanks are due to Ms. Gonlag and Mr. Smit, who performed the dead-end ultrafiltration experiments.

\section{Symbols}

$\begin{array}{lll}A & \text { membrane area } & \left(\mathrm{m}^{2}\right) \\ C_{\mathrm{b}} & \text { concentration of the bulk } & \left(\mathrm{kg} / \mathrm{m}^{3}\right) \\ C_{\mathrm{bl}} & \text { (constant) concentration in the boundary layer } & \left(\mathrm{kg} / \mathrm{m}^{3}\right) \\ C_{\mathrm{g}} & \text { gel concentration } & \left(\mathrm{kg} / \mathrm{m}^{3}\right) \\ C_{\mathrm{m}} & \text { concentration at the membrane interface } & \left(\mathrm{kg} / \mathrm{m}^{3}\right) \\ C_{\mathrm{p}} & \text { concentration of the permeate } & \left(\mathrm{kg} / \mathrm{m}^{3}\right) \\ D & \text { diffusion coefficient } & \left(\mathrm{m}^{2} / \mathrm{sec}\right) \\ J_{\mathrm{v}} & \text { flux } & \left(\mathrm{m}^{3} / \mathrm{m}^{2} \mathrm{sec}\right) \\ J_{\mathrm{w}} & \text { clean water flux } & \left(\mathrm{m}^{3} / \mathrm{m}^{2} \mathrm{sec}\right) \\ p & \text { permeability of the boundary layer } & \left(\mathrm{m}^{2}\right) \\ r_{\mathrm{bl}} & \text { specific resistance of the boundary layer } & \left(\mathrm{m}^{-2}\right) \\ R_{\mathrm{obs}} & \text { observed retention coefficient } & \mathrm{dimensionless}^{-2} \\ R_{\mathrm{bl}} & \text { total hydraulic resistance of the boundary layer } & \left(\mathrm{m}^{-1}\right) \\ R_{\mathrm{m}} & \text { hydraulic resistance of the membrane } & \left(\mathrm{m}^{-1}\right) \\ s & \text { sedimentation coefficient } & \left(\mathrm{sec}^{-1}\right) \\ T & \text { temperature } & \left({ }^{\circ} \mathrm{C}\right) \\ v_{\mathrm{g}} & \text { partial specific volume of the solvent } & \left(\mathrm{m}^{3} / \mathrm{kg}\right) \\ v_{1} & \text { partial specific volume of the solute } & \left(\mathrm{m}^{3} / \mathrm{kg}\right) \\ V_{\mathrm{p}} & \text { (cumulative) permeate volume } & \left(\mathrm{m}^{3}\right)\end{array}$


$\alpha$

$\delta$

$\Delta P$

$\eta_{0}$ coordinate perpendicular to the membrane

$$
\text { slope } \mathrm{d}\left(1 / J_{\mathrm{v}}\right) / \mathrm{d}\left(V_{\mathrm{p}} / A\right)
$$

thickness of the boundary layer

applied pressure

viscosity of the solvent (m)

\author{
$\left(\mathrm{sec} / \mathrm{m}^{2}\right)$ \\ (m) \\ $(\mathrm{Pa})$ \\ (Pa sec)
}

\section{References}

1 S. Nakao, J.G. Wijmans and C.A. Smolders, Resistance to the permeate flux in unstirred ultrafiltration of dissolved macromolecular solutions, J. Membrane Sci., 26(1986) 165-178.

2 E. Matthiasson, The role of macromolecular adsorption in fouling of ultrafiltration membranes, J. Membrane Sci., 16(1983)23-36.

3 M.S. Le and J.A. Howell, Alternative model for ultrafiltration, Chem. Eng. Res. Des., 62(1984)373-380.

4 A. Suki, A.G. Fane and C.J.D. Fell, Modelling fouling mechanisms in protein ultrafiltration, J. Membrane Sci., 27 (1986)181-193.

5 V.L. Vilker, C.K. Colton and K.A. Smith, Concentration polarization in protein ultrafiltration, Part II: Theoretical and experimental study of albumin ultrafiltered in an unstirred batch cell, AIChE J., 27(1981)637-645.

6 G. Jonsson, Boundary layer phenomena during ultrafiltration of dextran and whey protein solutions, Desalination, 51(1984)61-77.

7 J.G. Wijmans, S. Nakao and C.A. Smolders, Hydrodynamic resistance of concentration polarization boundary layers in ultrafiltration, J. Membrane Sci., 22(1985)117-135.

8 W.F. Blatt, A. Dravid, A.S. Michaels and L. Nelsen, Solute polarization and cake formation in membrane ultrafiltration: causes, consequences and control techniques, in: J.E. Flinn (Ed.), Membrane Science and Technology, Plenum Press, New York, NY, 1970, pp. 47-97.

9 D.R. Trettin and M.R. Doshi, Ultrafiltration in an unstirred batch cell, Ind. Eng. Chem. Fundam., 19(1980)189-194.

10 P.F. Mijnlieff and W.J.M. Jaspers, Sovlent permeability of dissolved polymer material. Its direct determination from sedimentation experiments, Trans. Faraday Soc., 67 (1971) 18371854.

11 J.A. Howell and O. Velicangil, Theoretical considerations of membrane fouling and its treatment with immobilized enzymes for protein ultrafiltration. .J. Appl. Polym.. Sci., 27(1982)2132.

12 Fortran Library Manual, Mark 11, Vol. 2, Numerical Algorithms Group, 1984.

13 R.G. Kitchen, B.N. Preston and J.D. Wells, Diffusion and sedimentation of serum albumin in concentrated solutions, J. Polym. Sci., Polym. Symp., 55(1976)39-49.

14 J.L. Anderson, F. Rauh and A. Morales, Particle diffusion as a function of concentration and ionic strength, J. Phys. Chem., 82 (1978)608-616.

15 E.J. Cohn, J.A. Luetscher, J.L. Oncley, S.H. Armstrong and B.D. Davis, Preparation and properties of serum and plasma proteins, Part III, J. Am. Chem. Soc., 62(1940)3396-3400.

16 J.J.S. Shen and R.F. Probstein, On the prediction of limiting flux in laminar ultrafiltration of macromolecular solutions, Ind. Fng. Chem. Fundam., 16(1977)459-465.

17 G.D.J. Phillies, G.B. Benedek and N.A. Mazer, Diffusion in protein solutions at high concentrations: a study by quasielastic light scattering spectroscopy, J. Chem. Phys., $65(1976) 1883-1892$. 
18 B.D. Fair, D.Y. Chao and A.M. Jamieson, Mutual diffusion coefficients in bovine serum albumin solutions measured by quasiclastic laser light scattering, J. Colloid Interface Sci., 66(1978)323-330.

19 M.I. van Damme, W.D. Comper and B.N. Preston, Experimental measurements of polymer unidirectional fluxes in polymer + solvent systems with non-zero chemical-potential gradients, J. Chem. Soc., Faraday Trans., 78(1982)3357-3367.

20 H. Reihanian, C.R. Robertson and A.S. Michaels, Mechanisms of polarization and fouling of ultrafiltration membranes by proteins, J. Membrane Sci., 16(1983)237-258.

21 M.W. Chudacek and A.G. Fane, 'The dynamics of polarisation in unstirred and stirred ultrafiltration, J. Membrane Sci., 21 (1984) 145-160.

22 A.A. Kozinski and E.N. Lightfoot, Protein ultrafiltration: a general example of boundary layer filtration, AIChE J., 18(1972)1030-1040.

23 P. Dejmek, Concentration polarization in ultrafiltration of macromolecules, Ph.D. Thesis, University of Lund, Sweden, 1975. 